\title{
A Novel Approach to the Determination and Characterization of HIV Dementia
}

\author{
P. Brouwers, E. Mohr, K. Hildebrand, M. Hendricks, J.J. Claus, I.S. Baron, \\ M. Young and P. Pierce
}

\begin{abstract}
Background: Neuropsychological studies of the pattern and extent of cognitive impairment in HIV-infected patients have mostly used deviations from control values and/or cut-off scores as criteria for classification of dementia. There is, however, no agreement as to how to define impairment, and classification is imprecise. Method: The current study used a dementia classification matrix, developed with a step-wise linear discriminant analysis of neuropsychological data from patients with primary neurodegenerative dementias, to classify symptomatic HIV patients as demented or non-demented, and further to differentiate cortical and subcortical dementia patterns. Thirty-two male and 2 female patients (mean age $39 \pm 2$ ) with symptomatic HIV disease (mean absolute CD4 count $195 \pm 41$ ) participated in the study. Results: Thirty-five per cent of patients were classified as demented. Of these, $83 \%$ showed a subcortical pattern and $17 \%$ a cortical profile of deficits. Significant differences between patients classified as subcortically demented and those categorized as normal on neuropsychological measures associated with subcortical integrity further validated the classification. Measures of psychiatric status between subgroups were similar. Conclusion: Since certain treatments may delay or reverse cognitive deficits, the use of an objective classification method based on discriminant analysis may help to identify patients who may benefit from therapy.
\end{abstract}

RÉSUMÉ: Une approche nouvelle dans la détermination et la caractérisation de la démence associée à l'infection par le VIH. Introduction: Les études neuropsychologiques du type et de l'étendue du déficit cognitif chez les patients infectés par le VIH ont utilisé surtout l'écart par rapport à des valeurs contrôles et/ou des points de coupe comme critères de classification de la démence. Cependant, il n'y a pas de consensus sur la définition d'un déficit et la classification est imprécise. Méthode: La présente étude a utilisé une matrice de classification de la démence, développée par analyse discriminante linéaire séquentielle des données neuropsychologiques de patients présentant une démence neurodégénérative primaire, pour classifier les patients symptomatiques porteurs du VIH comme déments ou non-déments, et pour différencier des types de démence corticale et sous-corticale. Trente-deux hommes et deux femmes (âge moyen 39 2 ans) présentant une infection symptomatique par le VIH (décompte CD4 absolu moyen

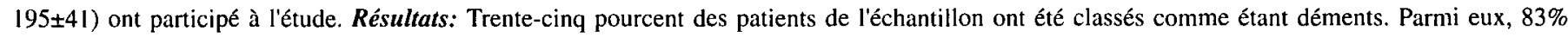
avaient un tableau de démence sous-corticale et $17 \%$ un tableau de démence cortical. Des différences significatives entre les patients classifiés comme présentant une démence sous-corticale et ceux classifiés comme normaux d'après les critères neuropsychologiques associés à l'intégrité sous-corticale ont confirmé la validité de la classification. Les mesures de l'état psychiatrique entre les sous-groupes étaient similaires. Conclusions: Comme il est possible que certains traitements puissent retarder ou même faire régresser les déficits cognitifs, l'utilisation d'une méthode de classification objective basée sur l'analyse discriminante peut constituer une aide diagnostique précieuse pour identifier les patients qui sont susceptibles de bénéficier d'une modification de leur traitement.

Can. J. Neurol. Sci. 1996; 23: 104-109

Neurobehavioral abnormalities have been described as frequent concomitants of infection with the human immunodeficiency virus type-1 (HIV). ${ }^{2,3}$ While such abnormalities are sometimes a consequence of opportunistic infections or neoplasms of the central nervous system (CNS), a number of reports indicate that the CNS is directly infected by HIV, ${ }^{4-6}$ often soon after initial systemic infection. ${ }^{7.8}$ Infection of the CNS may be associated with neurological symptoms such as the disabling cognitive impairment, motor dysfunction and behavioral changes defined as the AIDS Dementia Complex (ADC), or HIV-1-associated cognitive motor complex. ${ }^{9}$

ADC is secondary to the HIV disease process, indicating that only a limited number of infected patients will develop dementia, even in the final stages. Disease stage has, however, been linked to both the incidence and severity of ADC. Incidence rates of $20-90 \%$ have been reported in patients with late stage AIDS, while estimates range from $1-15 \%$ in asymptomatic HIV-infected individuals. ${ }^{10}$ Up to $10 \%$ of HIV-infected

From the Pediatric Branch, National Cancer Institute (P.B., M.H.); National Instutute of Neurologic Disorders \& Stroke (J.J.C.), National Institutes of Health, Bethesda, Maryland; University of Ottawa/Faculty of Medicine (E.M., K.H.), Ottawa; Georgetown University Medical Center (I.S.B., M.Y., P.P), Washington, DC RECEIVED MARCH 31, 1995. ACCEPTED IN FINAL FORM OCTOBER 17, 1995.

A preliminary portion of this study was presented at the 17th annual meeting of the International Neuropsychological Society, Vancouver, British Columbia, February $1989^{\prime}$ Reprint requests to: Dr. Pim Brouwers, Pediatric Branch, National Cancer Institute, NIH Clinical Center, Bldg 10, Rm 13N240, Bethesda, Maryland 20892 U.S.A. 
patients may present with ADC as the first manifestation of symptomatic disease. ${ }^{11,12}$ While many patients show impairments on neuropsychological tests as the disease progresses, type and extent of these deficits in asymptomatic HIV positive patients remains controversial. ${ }^{13-15}$

Studies of the pattern and extent of cognitive impairment in HIV positive patients have mostly used deviations from control values and/or cut-off scores as their criteria for classification of impairment or dementia (e.g. ${ }^{16-18}$ ). These approaches may be insufficient since classification accuracy is imprecise. Moreover, among these studies there is no clear agreement as to what level of cognitive functioning warrants a full diagnosis of dementia with its essential feature of impaired function in work and activities of daily living, as opposed to a finding of neuropsychological deficits that are of insufficient magnitude to significantly interfere with daily life. ${ }^{9,19}$

Recently we described a new methodology for the objective determination of the incidence and type of both primary and secondary dementia. ${ }^{20}$ The approach used a step-wise discriminant analysis (see Methods for description) for allocation to a diagnostic category using neuropsychological test scores. The method was developed using age-scaled neuropsychological test data from patients with primary neurodegenerative dementias of two different etiologies (Alzheimer's (AD) and Huntington's (HD) disease) and normal controls. A classification rule was derived that determined with high sensitivity $(100 \%)$ and specificity $(97 \%)$ whether a patient's functioning was indicative of the presence or absence of dementia. The formula further indicated if an individual's neuropsychological profile was more suggestive of subcortical (HD-like) or cortical (AD-like) demen$\operatorname{tia}^{21,22}$ (79\% correctly classified). The reliability of this classification formula was demonstrated with a new, independent sample of demented patients which yielded virtually identical results $(96 \%$ sensitivity for dementia; correct $\mathrm{AD} / \mathrm{HD}$ classification $78 \%$ ). Validity was demonstrated in 45 patients with Parkinson's disease (PD). The proportion of these PD patients classified as demented with the formula (38\%) was nearly identical to that reported in another recent study $(41 \%) .{ }^{23}$ Furthermore, comparisons were made between PD patients classified as demented and as non-demented on neuropsychological measures not included in the discriminant analysis. Significant differences between subgroups were ascertained and differential neuropsychological profiles were found which reflected their type of dementia classification.

The current study uses this methodology to classify patients with symptomatic HIV infection as demented or non-demented, and to determine whether those labelled demented evidence a predominantly subcortical or cortical pattern. To further validate the classifications and assess features of HIV dementia, subgroup differences are compared on additional neuropsychological variables not used in the discriminant function.

\section{METHODS}

\section{Patient Selection}

Thirty-four consecutive outpatients with symptomatic HIV infection consented to participate in this study, after full disclosure of potential risks and benefits. Patients with a history of IV drug use or other CNS abnormalities (opportunistic CNS infections, tumors, previous head trauma) were excluded due to the possibility of functional CNS sequelae independent of HIV infection. Assessments were carried out prior to any antiretroviral treatment, which has been shown to alter neuropsychological function. ${ }^{24-26}$ Patients with major psychiatric disorders (DSMIII-R criteria; by history) preceding infection were not eligible to participate. All participants were classified as having AIDS (Class IV) or AIDS Related Complex (ARC; Class III) based on Centers for Disease Control criteria. The mean \pm SEM absolute CD4 count was $195.4 \pm 41.0$ cells $/ \mathrm{mm}^{3}$. Subjects included 32 males and 2 females whose mean age was 39.1 years (range 2265 years), with an average educational level of 15.3 years (range 11-19 years). Fifty-six per cent could be classified as visible minorities or women; 17 males and 1 female were non-caucasian, 15 males and 1 female were caucasian.

\section{Statistics and Test Battery}

The classification formula developed by Mohr et al. ${ }^{20}$ based on stepwise linear discriminant analysis was applied to the HIV patients to determine the incidence and subtype of dementia. Step-wise linear discriminant analysis allows the simultaneous comparison of several study groups on multiple variables. A subset of variables is combined into a mathematical equation, much like a linear regression equation, to predict group membership. Variables are entered into the equation successively (step-wise) on the basis of greatest discriminating power, until adding another variable does not significantly improve the predictive power of the equation. Age-scaled subtest scores (Block Design; Object Assembly; Digit Span) from the Wechsler Adult Intelligence Scale-Revised ${ }^{27}$ (WAIS-R) and the Memory Quotient and age-scaled Visual Reproduction subtest score from the Wechsler Memory Scale 28.29 (WMS) were included in the formula.

In addition, a comprehensive neuropsychological test battery covering a wide range of functions including cognition, motor performance and affect was administered. Tests not used for the discriminant function were used to compare HIV patients classified as 'demented' with those classified as 'normal' in order to assess the validity of the classifications and other features of cognitive function in patients with symptomatic HIV infection. Split-plot repeated measures analysis of variance (ANOVA) ${ }^{30}$ and Mann-Whitney-U tests were calculated to investigate further differentiating characteristics between subgroups.

\section{RESULTS}

\section{Classification of the HIV Patients}

Twenty-two of 34 HIV patients $(64.7 \%)$ were classified as 'normal' while $12(35.3 \%)$ were classified as 'demented' (Table 1). There was no significant difference between these two groups in disease stage, as reflected by their absolute CD4 counts (mean \pm SEM cells $/ \mathrm{mm}^{3}$ : normal HIV $199.5 \pm 45.0$; demented HIV $188.3 \pm 83.5$ ). Of the HIV patients classified as 'normal', 64\% had CD4 counts below 200, and 29\% had counts below 50 , while for those classified as 'demented', $75 \%$ were below 200 and $50 \%$ below 50 .

Of the patients classified as demented, $10(83.3 \%)$ showed a subcortical (HD-like) and $2(16.7 \%)$ a cortical (AD-like) pattern. This distribution was compared to that of the AD and HD 
Table 1: Classification of HIV patients using discriminant analysis of neuropsychological test scores, compared with the classification of patients with Alzheimer's and Huntington's disease and normal controls.

\begin{tabular}{lccc}
\hline Classification & AD-like & HD-like & NC-like \\
\hline Alzheimer's Disease $(\mathrm{n}=19)$ & $16(84 \%)$ & $3(16 \%)$ & $0(0 \%)$ \\
Huntington's Disease $(\mathrm{n}=19)$ & $5(26 \%)$ & $14(74 \%)$ & $0(0 \%)$ \\
Normal Controls $(\mathrm{n}=29)$ & $0(\%)$ & $1(3 \%)$ & $28(97 \%)$ \\
HIV Disease (AIDS/ARC; $\mathrm{n}=34)$ & $2(6 \%)$ & $10(29 \%)$ & $22(65 \%)$ \\
\hline
\end{tabular}

Results for AD and HD patients and normal controls are from a previous study. ${ }^{20}$

patients and normal controls used to develop the classification matrix (Table 1). ${ }^{20}$ The distributions of the HIV (demented) and Alzheimer's patients showed significant differences $\left(\chi^{2}=11.1\right.$; $\mathrm{p}<.001$ ). In contrast, the distributions of the HIV (demented) and Huntington's patients were highly similar $\left(\chi^{2}=0.03 ; \mathrm{p}>.50\right)$, suggesting that the HIV impairment profile is principally 'HDlike'.

\section{Comparison of HIV Patient Subgroups}

Further analyses contrasting HIV patients classified as HD-like with those classified as 'normal control-like' (NC-like) were calculated (Table 2). (Since only 2 HIV patients were classified as $\mathrm{AD}$-like, no reliable comparisons between this subgroup and the other two subgroups could be computed.) Contrast of patient characteristics for the two subgroups did not show any significant demographic differences or differences in degree of immunosuppression as measured by CD4 cell counts.

Global intellectual ability (assessed non-verbally with the Raven's Progressive Matrices-Revised ${ }^{31}$ ) revealed significantly greater decrements in those classified as HD-like (mean standard score $=99 \pm 4.3$ ) compared to those identified as NC-like $(121 \pm 2.3 ; \mathrm{p}<.001)$.

Language function, tested with the Peabody Picture Vocabulary Test-Revised ${ }^{32}$ (PPVT-R) and the Wide Range Achievement TestReading ${ }^{33}$ (WRAT-R), also revealed greater decrements in those classified as HD-like, compared to NC-like symptomatic HIV patients (mean standard scores - PPVT-R: HD 91.2 \pm 4.7 ; NC $116.9 \pm 3.1 ; \mathrm{p}<.001$; WRAT-R: HD $86.5 \pm 5.5$; NC $110.9 \pm 2.1$; $\mathrm{p}<.001$ ). On a verbal fluency task (Thurstone Chicago Fluency, ${ }^{34}$ 5 minutes with ' $S$ '), the difference was borderline (mean number of words produced: HD $32.1 \pm 4.1$; NC 43.0 \pm 3.3 ; $p<.06$ ).

Visuospatial function was assessed with the Streetmap Test, ${ }^{35}$ which requires right/left discrimination with and without mental rotation. The latter involves the manipulation of the internal representation of an object such that different points of view can be appreciated. Significant differences between the two subgroups were found (mean total number of errors: HD $6.5 \pm 1.97$; NC $2.5 \pm .59 ; \mathrm{p}<.05$ ). Both groups identified left/right turns with equal accuracy in the away from the subject direction. However, when egocentric rotation was required, (direction reversed to towards the subject), the HD-like group had a significantly increased mean number of errors $(2.70 \pm .60)$ compared to the NC-like group $(0.64 \pm .40 ; \mathrm{p}<.01)$ (Figure)

Measures of attention and psychomotor speed yielded variable results. In Trail Making ${ }^{36}$ Test $\mathrm{A}$, mean completion time
Table 2: Comparison of HIV patients classified as HD-like with those classified as NC-like.

\begin{tabular}{|c|c|c|c|}
\hline Classification & $\begin{array}{c}\text { HD-like } \\
\text { Mean (range) }\end{array}$ & $\begin{array}{c}\text { NC-like } \\
\text { Mean (range) }\end{array}$ & $\mathbf{p}$ \\
\hline \multicolumn{4}{|l|}{ Patient Characteristics } \\
\hline Male/Female & $9 / 1$ & $21 / 1$ & NS \\
\hline Education (years) & $14.1(11-18)$ & $16.1(12-19)$ & $>.15$ \\
\hline Age (years) & $36.0(29-50)$ & $41.9(22-65)$ & $>.16$ \\
\hline $\mathrm{CD} 4\left(\mathrm{cells} / \mathrm{mm}^{3}\right)$ & $218.5(2-847)$ & $199.5(13-764)$ & NS \\
\hline \multicolumn{4}{|l|}{ Neuropsychological Tests } \\
\hline \multicolumn{4}{|l|}{ Intellectual Function } \\
\hline WAIS-R FSIQ* & $86.1(66-100)$ & $110.0(88-130)$ & $<.001$ \\
\hline WAIS-R VIQ* & $87.4(66-98)$ & $111.6(85-128)$ & $<.001$ \\
\hline WAIS-R PIQ* & $87.0(70-104)$ & $106.0(92-125)$ & $<.001$ \\
\hline Ravens Matrices & $99.0(67-116)$ & $121.0(102-139)$ & $<.001$ \\
\hline \multicolumn{4}{|l|}{ Memory } \\
\hline WMS Memory Quotient* & $92.0(72-107)$ & $119.8(107-137)$ & $<.001$ \\
\hline \multicolumn{4}{|l|}{ Language } \\
\hline Peabody PVT-R & $91.2(64-112)$ & $116.9(79-143)$ & $<.001$ \\
\hline WRAT-Reading & $86.5(48-101)$ & $110.9(81-129)$ & $<.001$ \\
\hline Word Fluency & $32.1(10-51)$ & $43.0(24-88)$ & $<.06$ \\
\hline \multicolumn{4}{|l|}{ Visuospatial Function } \\
\hline Streetmap Total Errors & $6.5(1-21)$ & $2.5(0-12)$ & $<.05$ \\
\hline Streetmap Errors Up-Down & $2.7(1-6)$ & $0.6(-5-4)$ & $<.01$ \\
\hline \multicolumn{4}{|l|}{ Attention/Psychomotor Speed } \\
\hline Trail-Making Test A (time) & 21.2 & 17.4 & NS \\
\hline Trail-Making Test B (time) & 153.8 & 68.9 & $<.01 * *$ \\
\hline Reaction Time Simple & 269.8 & 259.8 & NS \\
\hline Reaction Time Choice & 413.8 & 409.0 & NS \\
\hline Decision Time (CRT-SRT) & 144.0 & 149.2 & NS \\
\hline \multicolumn{4}{|l|}{ Mood Affect } \\
\hline Beck Depression & 13.3 & 11.1 & NS \\
\hline MAACL -Depression & 74.3 & 66.0 & NS \\
\hline -Anxiety & 69.9 & 66.0 & NS \\
\hline -Dysphoria & 71.8 & 63.4 & NS \\
\hline
\end{tabular}

*WAIS-R subtests Digit Span, Block Design, and Object Assembly and WMS Memory Quotient and Visual Reproduction were used in the discriminant classification matrix.

**Mann-Whitney-U statistic; medians: HD 88.5; NC 68.5.

was $21.2 \pm 3.9(\mathrm{HD})$ versus $17.4 \pm 1.3(\mathrm{NC})$, a difference which did not reach statistical significance. Trail Making Test B scores on the other hand were significantly different (Mann-Whitney$\mathrm{U}, \mathrm{p}<.01$; median completion time (seconds): HD 88.5, NC 68.5; a non-parametric test was used for this variable because scores were not normally distributed). In the Reaction Time Test, differences were not significant between the HD-like and NC-like groups, either in Simple Reaction Time (HD $270 \pm 23$; NC $260 \pm 11$ ), Choice Reaction Time (HD $414 \pm 29$; NC $409 \pm$ 28 ) or Decision Time (HD $144 \pm 13$; NC $149 \pm 22$ ).

Analysis of affective variables with the Beck Depression Scale $^{37}$ and the Multiple Affect Adjective Checklist (MAACL) indicated that although most patients showed elevated levels of depression and anxiety, there were no statistically significant differences in severity between subgroups. When evaluating the contribution of depression and anxiety to psychometric test 


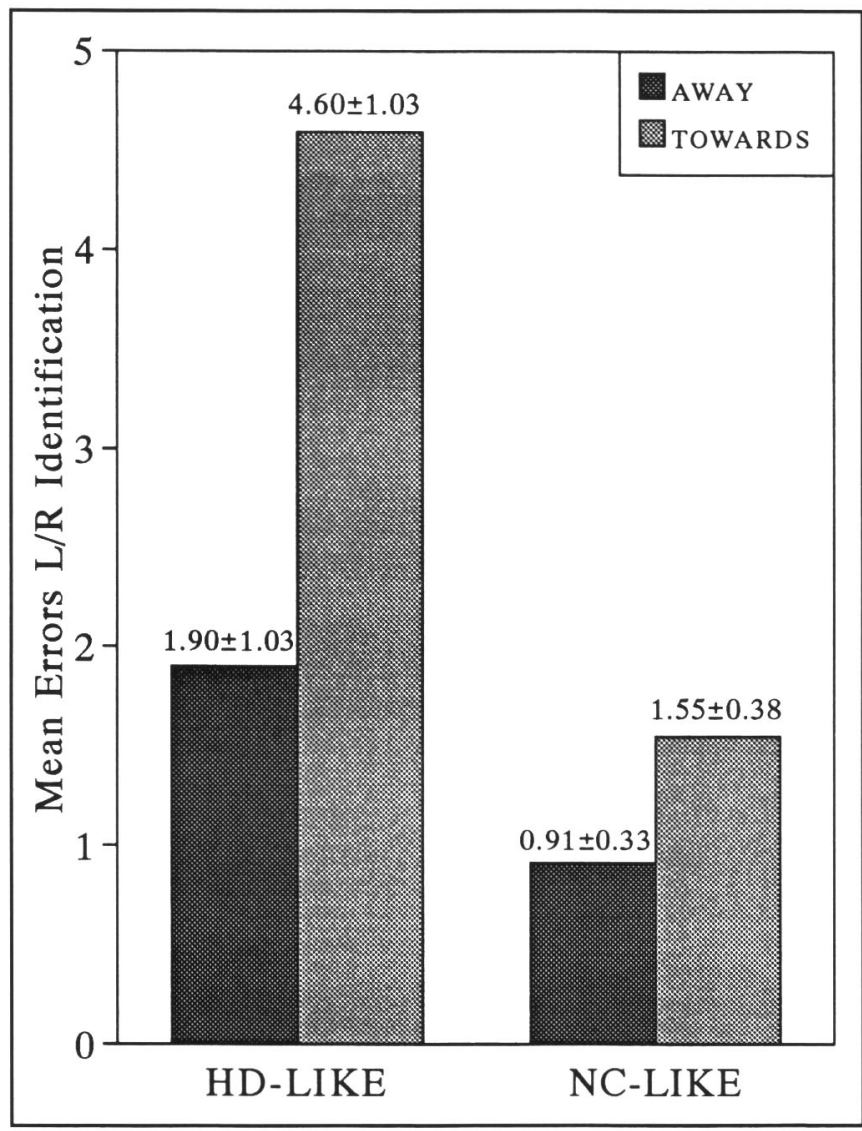

Figure: Comparison between HD-like and NC-like HIV patients on the Streetmap Test of Directional Sense (left/right identifications 'away' and 'towards' self).

results for all patients, the following correlations were observed with the Beck Depression Inventory: Ravens - 45 ; Trail Making A .44; Trail Making B .58; Street Map Up Errors .56; Street Map Down Errors .42 (all p's < .05). MAACL Anxiety showed borderline correlations with Reaction Time (Choice RT -.39, $\mathrm{p}<.05$; Simple RT $-.33, \mathrm{p}<.10$ ), suggesting that heightened anxiety may result in a quicker response time.

\section{Discussion}

\section{Discriminant Analysis}

The classification of HIV patients as demented or nondemented on the basis of a discriminant function with neuropsychological variables appears to offer a viable alternative to the use of cut-off scores or deviation from control values on multiple tests. Our approach offers greater precision as it is derived from objective, empirical data from patients with a confirmed diagnosis of primary neurodegenerative dementia, unlike a clinical approach which offers no clear objective criteria. A further advantage of this method is that the step-wise technique requires only limited neuropsychological testing and thus may serve well as a screening method. Dementia can be one of the first manifestations of symptomatic HIV disease $\mathrm{e}^{11.12}$ and the extent of deficits varies considerably, therefore this strategy may be useful in identifying these patients.

\section{Dementia Classification}

Application of this formula to patients with symptomatic HIV disease classified $35 \%$ as demented, which falls approximately in the mid-range of previous estimates. ${ }^{10}$ The absence of differences in CD4 values between the demented and nondemented HIV patients suggests that ADC is indeed a secondary process, i.e., it does not occur in all patients as the disease progresses.

Further subclassification of those identified as demented indicated that $83 \%$ showed a profile of deficits that was more compatible with a subcortical than a cortical dementia. Other studies have also suggested that subcortical structures may be predominantly involved in HIV-induced CNS disease. ${ }^{11,38.39}$ Autopsy reports of patients with primary HIV-induced CNS illness suggest that the core brain pathology occurs in the subcortical grey matter (basal ganglia, thalamus) and white matter tracts, with findings of white matter pallor, gliosis and multinucleated giant cells. ${ }^{4,40,41}$ Quantitative neuroimaging ${ }^{42}$ and positron emission tomography (PET) studies of the cerebral metabolic rate of glucose $\mathrm{S}^{43}$ have also tended to implicate subcortical structures in the disease and dementia. We have been able to demonstrate with PET that improvement of neuropsychological status in HIV patients occurred concurrently with increased glucose utilization in subcortical areas. ${ }^{24,44}$ These findings appear to further validate the results of our classification technique, supporting and extending the hypothesis of primarily subcortical involvement in CNS HIV disease.

\section{Subgroup Differences}

The validity of the classification approach is further supported by post-classification analysis of subgroup differences on measures not used in the discriminant function, which revealed significant differences between HD-like and NC-like HIV patients in tests of global intellect, language, attention and psychomotor and visuospatial function. The HD-like subgroup scored significantly lower on FSIQ, VIQ, PIQ, PPVT-R, WRAT-Reading, and Ravens Matrices than the NC-like subgroup, but there was also significant overlap between the two groups. This reflects the multidimensionality of the method of dementia classification, which is based on a complex analysis of neuropsychological profile rather than overall level of functioning. The relative deficit of the HD-like group on these tests of global cognitive function is suggestive of the presence of a more global CNS compromise along with subcortical involvement.

The significant visuospatial impairment in the ability to manipulate egocentric space as opposed to extrapersonal space on the Streetmap Test by patients identified with a subcorticaltype dementia further validates the classification obtained. In previous studies, we reported that HD patients, unlike AD patients, were impaired to a significantly greater degree when manipulation of egocentric as opposed to extrapersonal space was required. ${ }^{45,46}$ Moreover, these studies showed that this discrepancy correlated with further progression of HD, perhaps in relation to nigrostriatal degeneration.

Slowness of response is a major feature of subcortical dementias ${ }^{21}$ and has also been a distinguishing characteristic of ADC. ${ }^{3,47.48}$ Accordingly in our study, performance on TrailMaking Test B, a task of psychomotor speed, was significantly slower in patients classified as demented (HD-like) than in nondemented patients. In Trail-Making $A$ and Reaction Time tests 
however, the non-demented and HD-like subgroups, although both slower than established norms, did not differ significantly. These results correspond to other recent studies, ${ }^{49-51}$ which found that while reaction time was slower in asymptomatic HIV positive patients (early stages) than in HIV negative controls, there was no significant correlation between disease stage (as reflected by CD4 counts) and reaction times in the HIV positive group, suggesting that further disease progression may not lead to further psychomotor slowing. These measures of attentional functioning therefore seem sensitive to HIV-associated CNS compromise in the earlier phases of the disease. However in later stages, such measures may be insensitive to further differentiation between AIDS patients with and without dementia. The discrepancy between the findings on Trail-Making B and Reaction Time tests may also be due to a difference in task requirements. Reaction Time tests are relatively simple externally-paced stimulus-response tasks, while the TrailMaking Test B is a self-paced task requiring more complex response-set shifting behaviors.

Depression can be a behavioral concomitant of subcortical dementia. ${ }^{21}$ Although most of the HIV patients in the current study showed evidence of depression, there were no significant differences between patients classified as demented (HD-like) or normal on the various depression and anxiety measures. Depression and anxiety can also have significant effects on neurocognitive functioning. The lack of a difference between subgroups again suggests that these behaviors did not significantly influence the dementia classification. Thus deficits in neuropsychological functioning in patients with HIV disease appear to be relatively independent from abnormalities in mood, as other investigators have also found. ${ }^{6.52-54}$

Cognitive manifestations may become a more critical aspect of HIV disease as advances in anti-retroviral therapy as well as in prophylactic and direct treatment of opportunistic infection lead to longer survival for these patients. ${ }^{55}$ The detection of significant CNS compromise in patients with symptomatic HIV disease is important for timely commencement of anti-retroviral therapy. Studies have shown that for both pediatric and adult patients, improvements in neurocognitive function can be achieved with anti-retroviral treatments such as zidovudine (ZVD) ${ }^{24.25 .55-57}$ These studies, however, also indicate that CNS efficacy is dependent in part on pharmacological parameters such as dose, ${ }^{26}$ route of administration, ${ }^{58}$ absorption ${ }^{59}$ and CNS penetration. ${ }^{60}$ Thus the detection of significant CNS compromise in patients with symptomatic HIV disease may require treatment modification. In the absence of established biological markers for dementia, the use of an objective method to determine impaired neuropsychological functioning will be crucial. A method that can enhance diagnostic precision, evaluate progression and assess the effectiveness of pharmacological interventions is especially important given that a number of agents which may alleviate and even reverse neurological dysfunction are currently undergoing clinical trials. The classification approach used here may be one such method.

\section{ACKNOWLEDGEMENTS}

The work reported in this paper was in part supported by a grant (0354) from the American Foundation for AIDS Research. The contributions of Margaret Sampson and Mafalda Urbanyi are gratefully acknowledged.

\section{REFERENCES}

1. Brouwers $\mathrm{P}$, Mohr E, Hendricks M, Baron I. The use of discriminant analysis to differentiate the neuropsychological profile of HIV patients. J Clin Exp Neuropsychol 1989; 11: 35.

2. Navia BA, Jordan BD, Price RW. The AIDS dementia complex: I. Clinical features. Ann Neurol 1986; 19: 517-524.

3. Price RW, Brew B, Sidtis J, et al. The brain in AIDS: central nervous system HIV-1 infection and AIDS dementia complex. Science 1988; 239: 586-592.

4. Shaw GM, Harper ME, Hahn BH, et al. HTLV-III infection in brains of children and adults with AIDS encephalopathy. Science 1985; 227: 177-182.

5. Koenig S, Gendelman HE, Orenstein JM, et al. Detection of AIDS virus in macrophages in brain tissue from AIDS patient with encephalopathy. Science 1986; 233: 1089-1093.

6. Resnick L, DiMarzo-Veronese F, Schupbach J, et al. Intra-bloodbrain barrier synthesis of HTLV-III specific IgG in patients with neurological symptoms associated with AIDS or AIDS-related complex. N Engl J Med 1985; 313: 1498-1504.

7. Hollander H. Cerebrospinal fluid normalities and abnormalities in individuals infected with human immunodeficiency virus. $J$ Infect Dis 1988; 158: 855-858.

8. McArthur JC, Cohen BA, Farzedegan H, et al. Cerebrospinal fluid abnormalities in homosexual men with and without neuropsychiatric findings. Ann Neurol 1988; 23 (Suppl.): S34-S37.

9. American Academy of Neurology (AAN) AIDS Task Force. Nomenclature and research case definitions for neurologic manifestations of human immunodeficiency virus-type 1 infection. Neurology 1991; 41: 778-785.

10. Price RW, Brew BJ, Rosenblum M. The AIDS dementia complex and HIV-l brain infection: a pathogenetic model of virusimmune interaction. Res Publ Assoc Res Nerv Ment Dis 1990; 68: 269-290.

11. Brew BJ, Currie JN. HIV-related neurological disease. Med J Aust 1993; 158: 104-108.

12. Janssen RS, Nwanyanwu OC, Selik RM, Stehr-Green JK. Epidemiology of human immunodeficiency virus encephalopathy in the United States. Neurology 1992; 42: 1472-1476.

13. Grant I, Atkinson JH, Hesselink JR, et al. Evidence for early central nervous system involvement in the acquired immunodeficiency syndrome (AIDS) and other human immunodeficiency virus (HIV) infections. Studies with neuropsychologic testing and magnetic resonance imaging. Ann Intern Med 1987; 107: 828836.

14. McArthur JC, Cohen BA, Selnes OA, et al. Low prevalence of neurological and neuropsychological abnormalities in otherwise healthy HIV-1-infected individuals: results from the Multicenter AIDS Cohort Study. Ann Neurol 1989; 26: 601-611.

15. Selnes OA, Miller E, McArthur J, et al. HIV-I infection: no evidence of cognitive decline during the asymptomatic stages. Neurology 1990; 40: 204-208.

16. Bornstein RA, Pace P, Rosenberger P, et al. Depression and neuropsychological performance in asymptomatic HIV infection. Am J Psychiatry 1993; 150: 922-927.

17. Wilkie FL, Eisdorfer C, Morgan R, Loewenstein DA, Szapocznik J. Cognition in early human immunodeficiency virus infection. Arch Neurol 1990; 47: 433-440.

18. Lunn $S$, Skydsbjerg M, Schulsinger $\mathbf{H}$, et al. A preliminary report on the neuropsychologic sequelae of Human Immunodeficiency Virus. Arch Gen Psychiatry 1991; 48: 139-142.

19. Adams KM, Heaton RK. Statement concerning the NIMH neuropsychological battery. J Clin Exp Neuropsychol 1990; 12: 960962.

20. Mohr E, Brouwers P, Claus JJ, et al. Differential classification of dementia. Behavioural Neurology 1995; 8: 23-30.

21. Cummings JL. Subcortical Dementia, New York: Oxford University Press, 1990:

22. Tolosa ES, Alvarez R. Differential diagnosis of cortical vs. subcortical dementing disorders. Acta Neurol Scand 1992; 139: 47-53.

23. Mayeux R, Denaro J, Hemenegildo N, et al. A population-based investigation of Parkinson's disease with and without dementia: relationship to age and gender. Arch Neurol 1992; 49: 492-497. 
24. Yarchoan R, Berg G, Brouwers P, et al. Response of HumanImmuodeficiency-Virus-associated neurological disease to 3'Azido-3'-Deoxythymidine. Lancet 1987; 1: 132-135.

25. Schmitt F, Bigley J, McKinnis R, et al. Neuropsychological outcome of zidovudine (AZT) treatment of patients with AIDS and AIDS-related complex. N Engl J Med 1988; 319: 1573-1578.

26. Sidtis JJ, Gatsonis C, Price RW, et al. Zidovudine treatment of the AIDS dementia complex: results of a placebo-controlled trial. Ann Neurol 1993; 33: 343-349.

27. Wechsler D. Wechsler Adult Intelligence Scale-Revised, New York: The Psychological Corporation, 1981.

28. Wechsler D, Stone CP. Wechsler Memory Scale, New York: The Psychological Corporation, 1945.

29. Osborne D, Davis LJ. Standard Scores for Wechsler Memory Scale Subtests. J Clin Psychol 1978; 34: 115-116.

30. Kirk RE. Experimental design: procedures of the behavioral sciences, Belmont, CA: Brooks/Cole Publishing Co., 1968.

31. Raven JC. Guide to Using the Coloured Progressive Matrices. London: H.K. Lewis, 1965.

32. Dunn LM. Peabody Picture Vocabulary Test - Revised Manual, Circle Pines, MN: American Guidance Service, 1981.

33. Jastak S, Wilkinson G. The Wide Range Achievement TestRevised: Administration Manual, Wilmington, DE: Jastak Associates, 1984.

34. Spreen O, Benton AL. Neurosensory Center Comprehensive Examination for Aphasia (NCCEA), Victoria: University of Victoria, Neuropsychology Laboratory, 1977.

35. Money JA. Standardized Road Map of Direction Sense, San Rafael, CA. Academic Therapy Publications, 1976.

36. Lezak MD. Neuropsychological Assessment, 2nd edition. New York: Oxford University Press, 1983.

37. Beck AT, Ward CH, Mendelson M, Mock J, Erbaugh J. An inventory for measuring depression. Arch Gen Psychiatry 1961; 4: $561-571$.

38. Navia BA. The AIDS dementia complex. In: Cummings JL, ed. Subcortical Dementia, New York: Oxford University Press, 1990: 181-198.

39. Chui HC. Dementia: a review emphasizing clinicopathologic correlation and brain - behavior relationships. Arch Neurol 1989; 46: 806-814.

40. Navia BA, Cho ES, Petito CK, Price RW. The AIDS dementia complex: II. Neuropathology. Ann Neurol 1986; 19: 525-535.

41. Budka H, Costanzi G, Cristina S, et al. Brain pathology induced by infection with the human immunodeficiency virus (HIV): a histological, immunocytochemical, and electron microscopical study of 100 autopsy cases. Acta Neuropathol 1987; 75: 185198.

42. Aylward EH, Henderer JD, McArthur JC, et al. Reduced basal ganglia volume in HIV-1-associated dementia: results from quantitative neuroimaging. Neurology 1993; 43: 2099-2104.

43. Rottenberg DA, Moeller JR, Strother SC, et al. The metabolic pathology of the AIDS dementia complex. Ann Neurol 1987; 22: 700-706.

44. Brunetti A, Berg G, Di Chiro G, et al. Reversal of brain metabolic abnormalities following treatment of AIDS dementia complex with 3'-azido-2',3'-dideoxythymidine (AZT, zidovudine): a PET-FDG study. J Nucl Med 1989; 30: 581-590.
45. Brouwers P, Cox CS, Martin A, Chase TN, Fedio P. Differential perceptual-spatial impairment in Huntington's and Alzheimer's dementias. Arch Neurol 1984; 41: 1073-1076.

46. Mohr E, Brouwers $\mathrm{P}$, Claus JJ, et al. Visuospatial cognition in Huntington's disease. Mov Disord 1991; 6: 127-132.

47. Perdices M, Cooper DA. Simple and choice reaction time in patients with human immunodeficiency virus infection. Ann Neurol 1989; 25: 460-467.

48. Miller EN, Satz P, Visscher B. Computerized and conventional neuropsychological assessment of HIV-1 infected homosexual men. Neurology 1991; 41: 1608-1616.

49. Wilkie FL, Morgan R, Fletcher MA, et al. Cognitive and immune function in HIV-1 infection. AIDS 1992; 6: 977-981.

50. Martin A, Heyes MP, Salazar AM, et al. Progressive slowing of reaction time and increasing cerebrospinal fluid concentrations of quinolinic acid in HIV-infected individuals. Neuropsychiatr Clin Neurosci 1992; 4: 270-279.

51. Podraza AM, Bornstein RA, Whitacre CC, et al. Neuro-psychological performance and CD4 levels in HIV-1 asymptomatic infection. J Clin Exp Neuropsychol 1994; 16: 777-783.

52. Grant I, Atkinson JH. Neurogenic and psychogenic behavioral correlates of HIV infection. Res Publ Assoc Res Nerv Ment Dis 1990; 68: 291-304.

53. Hollander $H$. Neurologic and psychiatric manifestations of HIV disease. J Gen Int Med 1991; 6 (Jan/Feb Suppl.): S24-S31.

54. Rubinow DR, Berrettini $\mathrm{CH}$, Brouwers $\mathrm{P}$, Lane HC. Neuropsychiatric consequences of AIDS. Ann Neurol 1988; 23 (Suppl.): S24-S26.

55. Schmitt FA, Dickson LR, Brouwers P. Neuropsychological response to anti-retroviral therapy in HIV infection. In: Grant $I$, Martin A, eds. Neuropsychology of HIV infection: current research and new directions, Oxford: Oxford University Press, 1994: 276-294.

56. Pizzo PA, Eddy J, Falloon J, et al. Effect of continuous intravenous infusion of zidovudine (AZT) in children with symptomatic HIV infection. N Engl J Med 1988; 319: 889-896.

57. Yarchoan R, Pluda JM, Thomas RV, et al. Long-term toxicity/activity profile of 2',3'-dideoxyinosine in AIDS or AIDS-related complex. Lancet 1990; 336: 526-529.

58. Brouwers $\mathrm{P}$, Moss $\mathrm{H}$, Wolters $\mathrm{P}$, et al. Effect of continuous-infusion zidovudine therapy on neuropsychologic functioning in children with symptomatic human immuno-deficiency virus infection. J Pediatr 1990; 117: 980-985.

59. Balis FM, Pizzo PA, Butler KM, et al. Clinical pharmacology of 2', 3'-dideoxyinosine in human immunodeficiency virus-infected children. J Infect Dis 1992; 165: 99-104.

60. Brouwers P, DeCarli C, Tudor-Williams G, et al. Interrelations among patterns of change in neurocognitive, CT brain imaging, and CD4 measures associated with anti-retroviral therapy in children with symptomatic HIV infection. Adv Neuroimmunol 1994; 4: 223-231. 